\title{
Understanding and representing 'place' in health research: A relational approach
}

\author{
Steven Cummins ${ }^{\mathrm{a}, *}$, Sarah Curtis ${ }^{\mathrm{b}}$, Ana V. Diez-Roux ${ }^{\mathrm{c}}$, Sally Macintyre ${ }^{\mathrm{d}}$ \\ ${ }^{a}$ Department of Geography, Queen Mary, University of London, Mile End Road, London, UK \\ ${ }^{\mathrm{b}}$ Department of Geography, University of Durham, Durham, UK \\ ${ }^{\mathrm{c}}$ Center for Social Epidemiology \& Population Health, Department of Epidemiology, School of Public Health, \\ University of Michigan, Ann Arbor, MI, USA \\ ${ }^{\mathrm{d}}$ MRC Social \& Public Health Sciences Unit, Glasgow, UK
}

Available online 13 August 2007

\begin{abstract}
Epidemiology, sociology, and geography have been successful in re-establishing interest in the role of place in shaping health and health inequalities. However, some of the relevant empirical research has relied on rather conventional conceptions of space and place and focused on isolating the "independent" contribution of place-level and individual-level factors. This approach may have resulted in an underestimate of the contribution of 'place' to disease risk. In this paper we argue the case for extensive (quantitative) as well as intensive (qualitative) empirical, as well as theoretical, research on health variation that incorporates 'relational', views of space and place. Specifically, we argue that research in place and health should avoid the false dualism of context and composition by recognising that there is a mutually reinforcing and reciprocal relationship between people and place. We explore in the discussion how these theoretical perspectives are beginning to influence empirical research. We argue that these approaches to understanding how place relates to health are important in order to deliver effective, 'contextually sensitive' policy interventions.
\end{abstract}

(C) 2007 Elsevier Ltd. All rights reserved.

Keywords: Place; Space; Neighbourhood effects; Relational theory; Geography

\section{Introduction}

The idea that 'context' matters for individual health is not new and has its roots in the holistic, Hippocratic tradition of medicine (Macintyre \& Ellaway, 2003; Meade \& Earickson, 2002). However, it is particularly since the early 1990 s that we have seen a considerable expansion of theoretical

\footnotetext{
*Corresponding author. Tel.: + 442078825400.

E-mail addresses: s.c.j.cummins@qmul.ac.uk (S. Cummins), s.e.curtis@qmul.ac.uk (S. Curtis), adiezrou@umich.edu (A.V. Diez-Roux), sally@msoc.mrc.gla.ac.uk (S. Macintyre).
}

and empirical work investigating the role of contextual factors in the production and maintenance of health variation. Geographers and sociologists have long argued that place is relevant for health variation because it constitutes as well as contains social relations and physical resources (Jones \& Moon, 1993; Kearns, 1993; Kearns \& Joseph, 1993; Macintyre, McIver, \& Sooman, 1993). This re-engagement with the idea that 'place', as well as the characteristics of individuals, contributes to health variation appeared to arise simultaneously in geography, sociology and epidemiology and researchers within each of these disciplines have 
since made significant contributions to the development of knowledge in this field (see also Curtis \& Rees-Jones, 1998; Diez-Roux, 1998, 2000; Macintyre, Ellaway, \& Cummins, 2002 for further reviews). In this paper we aim to highlight selected examples of empirical research investigating associations between place and health that, implicitly or explicitly, incorporate 'relational' views of context and space. Relational conceptions of space and place have recently emerged in theoretical discussions in geography and other disciplines and here we argue that further development of these theoretical approaches could help to improve the empirical evidence about how 'place' matters for health.

A significant amount of empirical research on health and place has applied extensive, quantitative methods and techniques for statistical modelling of a general 'contextual' effect (usually of deprivation) on the health of populations (reviewed, for example in: Chaix, Merlo, \& Chauvin, 2005; Chaix, Rosvall, Lynch, \& Merlo, in press; Duncan \& Jones, 1993; Diez-Roux, 1998, 2004; Raudenbush \& Sampson, 1999; Sampson, Morenoff, \& Gannon-Rowley, 2002; Subramanian, Jones, \& Duncan, 2003). However recent advances in 'place-based' health research have focused on the articulation and development of plausible conceptual models of the causal pathways by which 'place' (especially place of residence) may influence health and there has been a growing emphasis on the importance of establishing empirical evidence to substantiate these theories, partly in response to the drive to make public health policy more 'evidence based'. Some recent studies have used qualitative methods to research individuals' experience and perceptions of place and what these mean for health (for example, Airey, 2003; Berkman, Glass, Brissette, \& Seeman, 2000; Frohlich, Corin, \& Potvin, 2001; Frohlich, Potvin, Chabot, \& Corin, 2002; Popay, Williams, Thomas, \& Gatrell, 1998; Popay, Thomas, Williams, Bennett, Gatrell, \& Bostock, 2003). These qualitative studies are valuable because they provide insights that show us how conditions in particular places are thought to influence health and health related behaviour, and they are powerfully suggestive of causal pathways relating environmental factors to individual health. Quantitative studies are also now beginning to take such an approach by testing hypotheses regarding how specific features of places (e.g. features of the built or social environments) are related to relevant health-related outcomes (for example Addy et al., 2004; Giles-Corti \& Donovan, 2003). This research is valuable because in order to design policies that improve public health we need to be able to estimate the magnitude of such relationships and understand how far relationships between health and places are generalizable (or variable) across whole populations. In addition, understanding the specific mechanisms through which places affect health, as well as quantifying their impact, is important not only for strengthening causal inferences but also for identifying potential avenues for intervention.

Much of the early research concentrated on exploring whether places do indeed 'matter' for health variation and the extent to which they produce significant health inequalities. In retrospect, this analytical focus has had the unintended consequence of constructing places and people (or 'context' and 'composition') as mutually exclusive and competing explanations for health inequality (Macintyre et al., 2002). Although there are a number of notable exceptions, which we discuss below, we tend to concur with Smith and Easterlow (2005) that empirical research has often been limited because it has tended to rely too much on rather conventional representations of space and place. These aspects may explain why, for example, the majority of quantitative studies find only a small proportion of health variation attributable to 'context' when compared to conventional, individual level risk factors (Pickett \& Pearl, 2001) and why, despite significant advances in research on health and place, the empirical evidence on what specific aspects of context matter for which health outcomes remains relatively weak. It may be argued (for example Carpiano, 2006) that better theoretical frameworks in health research need to be tested through empirical research, before robust 'contextual' interventions to improve health can be designed and implemented. We argue below that research which employs ideas about 'relational geographies' may help to provide us with this evidence. Our discussion here elaborates first on the key theoretical aspects of a 'relational' geographical perspective and then considers how this might be 'operationalized' through research methodologies, particularly in the field of quantitative research, where, we argue, a 'relational' perspective might bring the most benefit.

\section{Key dimensions of relational geographies}

This paper does not aim to propose major new theories about how we should understand and 
represent relational aspects of place and space; we are more concerned with discussing how these ideas have been, and could be, further applied in research on health inequalities. Fig. 1 briefly summarises some key differences between 'relational' and 'conventional' views of place, and we accept that, for illustrative purposes, it may over-emphasize the 'extremes' of these different perspectives in order to distinguish between the perspectives we outline here. A relational perspective on health and place encourages us to imagine places in terms of the ideas on the right of Fig. 1, rather than those on the left. In this section we briefly summarize the justification for these elements although, within the limitations of this paper, we are only able to briefly outline this literature.

Several geographers have argued that places may be more usefully viewed as nodes in networks than as discrete and autonomous bounded spatial units. Thus, authors such as Massey (1999), Graham \& Healy (1999), Watts (1999, 2000), Castree (2004) discuss space as unstructured, unbounded and freely connected and emphasise that human practice forms 'constellations of connections' which extend outwith the traditional 'bounded' notion of place (Massey, 2005, p. 187), echoing these views Hudson (2004, p. 462) describes these nodes/networks as a 'complex circuitry with a multiplicity of linkages and feedback loops'. Murdoch (1998, p. 357) discusses how far Actor Network Theory (as elaborated by Latour, 1996) "gives rise to a new kind of geography ... or geographical analysis." $\mathrm{He}$ comments on Latour's (1996) suggestion that a concept of geography defined by distance, measured in conventional Euclidean terms, would be inconsistent with this theory and explains how developments in (relational) geographical theory seeks to elaborate and extend traditional notions of proximity and distance as defining the separation of people and places. Authors such as Marston, Jones, and Woodward (2005) and Jonas (2006) have also debated the contemporary relevance of the conventional geographical preoccupation with scale, and particularly the preoccupation with distinguishing local, as opposed to global contexts and processes. Jonas, in particular, appears to suggest that a more sophisticated perspective would involve more analysis of how human and physical phenomena need

\begin{tabular}{|l|l|}
\hline 'conventional' view & 'relational' view \\
\hline $\begin{array}{l}\text { spaces with geographical boundaries drawn } \\
\text { at a specific scale }\end{array}$ & Nodes in networks, multi-scale \\
\hline Separated by physical distance & Separated by socio-relational distance \\
\hline Resident local communities & $\begin{array}{l}\text { Populations of individuals who are mobile } \\
\text { daily and over their lifecourse }\end{array}$ \\
\hline $\begin{array}{l}\text { Services described in terms of fixed locations } \\
\text { often providing for territorial jurisdictions, } \\
\text { distance decay models describe varying } \\
\text { utility in space }\end{array}$ & $\begin{array}{l}\text { 'Layers' of assets available to populations via } \\
\text { varying paths in time and space. Euclidian } \\
\text { distance may not be relevant to utility. }\end{array}$ \\
\hline Area definitions relatively static and fixed & Area definitions relatively dynamic and fluid \\
\hline $\begin{array}{l}\text { Characteristics at fixed time points, e.g. } \\
\text { 'deprived' versus 'affluent' }\end{array}$ & $\begin{array}{l}\text { Dynamic characteristics e.g. 'declining' } \\
\text { versus 'advancing' }\end{array}$ \\
\hline $\begin{array}{l}\text { Culturally neutral territorial divisions, } \\
\text { infrastructure and services }\end{array}$ & $\begin{array}{l}\text { Territorial divisions, services and } \\
\text { infrastructure imbued with social power } \\
\text { relations and cultural meaning }\end{array}$ \\
\hline $\begin{array}{l}\text { Contextual features described systematically } \\
\text { groups }\end{array}$ & $\begin{array}{l}\text { Contextual features described variably by } \\
\text { different individuals and groups }\end{array}$ \\
\hline
\end{tabular}

Fig. 1. 'Conventional' and 'relational' understandings of 'place'. 
to be understood as an outcome of interrelated processes which may operate simultaneously at various spatial scales, whereas Murdoch, Marsden, and Banks (2000) discuss the influence of networks in terms of having long or short 'reach' and varying degrees of complexity. These authors stress the dynamic and changing characteristics of places and the place-to-place mobility of populations on a daily basis, and over the life-course. This implies that individuals often influence, and are influenced by, conditions in multiple places (for example see Massey's (2005) discussion of trajectories and Conradson and Latham's (2005) discussion of internationally mobile populations).

Most of these writers also emphasise the significance of power relationships for our understanding of place. The way that areas are delineated administratively, the distribution of services, infrastructure and linkages among places and the ways that places are represented are not seen as socially and politically neutral but as the outcome of dynamic social relations and power struggles between groups in society (Harvey, 1989, 1996). Hudson (2004, p. 463) discusses how “...spaces, flows and circuits are socially constructed, temporarily stabilized in time/space by the social glue of norms and rules, and both enable and constrain different forms of behaviour." Relational theorists have extended these arguments, showing that places are produced and maintained by the activities of 'actors', proximate or distal to a particular place, who operate individually or in concert across a wide range of geographical scales (Conradson, 2005). These 'actors' can be conceived of in a variety of ways from individuals and community organizations, firms and businesses, regional and national governments and institutions, peer-networks and families to static and dynamic regulatory structures and processes such as national tax policy and the rule of law. Thus, actors can be formal or informal and can even be conceived in a more abstract manner as a series of cultures, events and movements (such as health fads, protests, fashions and norms) that occur over time and which have a stable lineage (Emirbayer, 1997). Access to goods, services and other assets may be dependent partly on the geographical disposition of facilities and their jurisdictions but also on social networks and social power, interventions of various 'actors' and degrees of regulation which produce 'layers' of resources accessible to different members of local populations in different ways. Using Actor Network Theory,
Murdoch (1998) makes a distinction between 'spaces of prescription'-spaces which are relatively prescribed in terms of formalized and standardized control and organization of access to resourcesand 'spaces of negotiation' - spaces which may be much more fluid in the way that human activity and resources are organized. Thus the characteristics of areas and the people within them are dynamic in time, as well as in space. The perceived significance of specific area attributes and the networks that link people differ and therefore will influence individuals and social groups in varying ways. Also (Murdoch et al., 2000, p. 113) argue that Actor Network Theory tends not to invoke a dualism between the global and the local, but rather interprets the power of networks in terms of 'long' and 'short' reach and in terms of the complexity of the network. Furthermore the maintenance of large complex networks is presented as a 'struggle' rather than a clearly dominating position. Convention theory identifies different practices, routines and agreements that help to determine action. Citing Salais and Storper (1993), Murdoch et al. (2000) discuss these in conjunction with the idea of 'embeddedness'.

In the following sections we review a selection of research in order to elaborate on what could possibly comprise a relational view of place and how it would influence empirical, as well as theoretical, research on health. We argue that in order to operationalize these 'relational' conceptions of place it will be necessary to move away from empirical research designed to distinguish between contextual and compositional effects and instead concentrate on the processes and interactions occurring between people and places and over time which may be important for health. Fostering a relational perspective will also require a reassessment of existing articulations of location and scale that have been typically used in the study of health and place in the past.

\section{Moving beyond context and composition: reconnecting people and place}

In an earlier paper, two of the current authors asked whether it was still useful to establish the relative importance of context over composition for health (Macintyre et al., 2002). This earlier paper chiefly urged researchers not to inadvertently control for, or overlook the intervening variables which might mediate the causal pathways between 
place and health and highlighted the lack of prespecified a priori theories of contextual causal mechanisms in epidemiological models. In addition, the characteristics of persons and the contexts (and places) they live in are tightly interrelated. For example, the lives of children growing up in a particular neighbourhood may be shaped by the social and material aspects of the neighbourhood (prevailing social norms and values, the built environment, educational provision and standards): but the social interactions and behaviour of these children, and how as adults they might operate in the same neighbourhood, also shapes the local social and physical environment and helps create 'context' for their neighbours.

These tight interrelationships between individuals and contexts, are not easy to capture in quantitative studies (Mitchell, 2001). This is partly why some researchers have adopted important alternative methodological strategies such as qualitative techniques. Such studies have generated insights into understanding the processes by which 'context' gets 'into the body' through theoretical constructs such as 'knowledgeable lay narratives' (Popay et al., 1998; Popay, Thomas et al., 2003) and 'collective' lifestyles (Frohlich et al., 2001, 2002). However, these perspectives about how places are produced and maintained, and how individuals relate to them, and what this means for the health of individuals who reside there remain poorly integrated into empirical research.

Though statistical modelling is unlikely to be able to capture all the nuances and detail that can be observed with qualitative approaches, qualitative findings do suggest that quantitative epidemiological studies of context should investigate more carefully the extent of interactions between characteristics of individuals and the features of places associated with varying health risks (see Davidson \& Hunt, 2006). For example, multi-level models can be used to assess whether individual risk factors are equally significant in all settings, or whether they are more important in some types of place than in others. Shouls, Congdon, and Curtis (1996) undertook multi-level regression of inequalities in long term illness at the individual scale and found that differences in individual deprivation were more strongly associated with health outcomes in relatively affluent areas, compared with relatively poor areas. Fagg, Curtis, Congdon, and Stansfeld (2006) have used multi-level modelling, with interaction terms, to explore whether social support has different impacts according to the socio-economic environment. At the macro scale of country level analyses, a number of research studies reviewed by Wilkinson and Pickett (2006) have used statistical methods to explore how far overall variability in income and other aspects of socio-economic position in societies interacts with the individual association between poverty and health. For these statistical tests of interactions to be informative however, the will need to be based on a priori theory and must use study designs and data structures that ensure sufficient power to detect these interactions.

Another interesting illustration of the complex interrelationship between individual characteristics and collective social conditions comes from research exploring the idea that 'ethnic density' (neighbourhood concentration of people belonging to a particular minority group) may also be important for health (Fagg, Curtis, Congdon et al., 2006; Neeleman, Wilson-Jones, \& Wessely, 2005; Subramanian, Acevedo-Garcia, \& Osypuk, 2005). These studies involve separate analyses for different ethnic groups, since geographical concentration of a particular ethnic group will have specific salience for individual members of that specific group and research reported by these authors suggests that the degree of concentration may affect the health of individual members of the group. Moderate concentration may have a protective effect on psychosocial health while very high concentrations are associated with more negative outcomes. This latter finding is only apparent in studies that have been carried out in certain urban settings where very high levels of concentration exist, so the potential to explore this relationship is in itself contingent on context. Health effects of ethnic concentration could also be different across ethnic groups (Eschbach, Mahnken, \& Goodwin, 2005). Work in this field is often cited as an illustration of the difficulty in theoretical terms of distinguishing and understanding what is meant by 'compositional' and 'contextual' effects; is ethnic concentration purely a question of 'composition' i.e. individuallevel risk factors associated with a particular ethnic group (such as low income), or does it operate through more subtle 'external' group-level environmental features that are associated with this concentration, such as culturally specific faith and community based facilities available to the group such as education, or the concentration of retail outlets offering products that support ethnically 
specific practices such as traditional diets and healthcare?

A further implication of the relational perspective is that we also need to incorporate information about settings that are drawn from reported views of residents, as well as from independently measured indicators of local conditions. We need more multi-dimensional research that combines multiple ways of characterizing and understanding places, including resident reports, systematic observation and objective measures on the location and spatial accessibility of resources (see for example, Hortulanus, 2000; Martinez, Black, \& Starr, 2002; Stafford, Cummins, Macintyre, Ellaway, \& Marmot, 2005). This kind of approach also requires the integration of qualitative research that gives us insights into how people relate to places and the resources available to them locally in order to develop more specific and nuanced hypotheses which can then be tested in quantitative analyses. For example, Davidson and Hunt (2006) demonstrate, using a qualitative approach, that the salience of differing dimensions of geographical areas (such as behaviour of local residents, structural factors, measures of relative deprivation between areas) depends upon the social groups to which they belong. Fagg, Curtis, Clark, Congdon, and Stansfeld (2007) have demonstrated that the varying mental health of individuals living in similar areas may influence their sensitivity to aspects of area deprivation.

\section{More than 'distance to resources': locating context in time and space}

We have argued above that conventional arguments about the relationship between distance and environmental effects on populations are beginning to be revised in the light of a relational perspective on place. This implies that we have to be much more careful in thinking how 'context' should be measured and move towards a more flexible and fluid approach to exposure assessment.

Matthews, Detwiler, and Burton's (2005) geoethnographic studies illustrate that access to resources for the maintenance of family life is not necessarily synonymous with geographical proximity. Fig. 2 shows that, for the families investigated by Matthews et al. (2005), the majority of social and material resources were external to the "neighbourhood' (over five miles away, in some cases) and varied in terms of the number of times each resource was accessed. These resources were both formal and informal and included material infrastructure such as medical services, day-care facilities and shopping opportunities to informal and spiritual sites such as religious institutions and the home locations of family and friends. Warfa et al. (2006) have also used individual data to demonstrate the complex trajectories of refugees over time, taking them in and out of different health service administrative jurisdictions and highlighting the high level of residential instability and insecurity for this group.

Using more extensive quantitative methods, Chaix et al. (2005) concluded from a study of health care utilization in France that place indicators better explained spatial variations in healthcare utilization when measured across continuous space, rather than within administrative areas. Kwan and colleagues (Kwan, 2004; Kwan \& Lee, 2004; Kwan, Murray, O'Kelly, \& Tielfelsdorf, 2003) have demonstrated this very effectively using newly developed space-time 'aquaria' generated in geographical information systems which show the highly individualized and complex spatial routines that people follow in their daily lives. This kind of work demonstrates that extending studies to include the measurement of individual exposure to multiple 'contexts' in time and space would be an important step forward. Charting an individual's movement around a more or less regularly frequented 'action space', over meaningful units of time (such as a day, week or month), would be crucial in helping to improve the estimation of exposure in contextual studies. These personal 'time-space biographies' would allow for the notion that movement (and thus exposure) varies from person to person and is associated with individual socio-demographic and cultural factors such as age, sex, employment status, ethnicity and religion. For example, an older, retired person may spend more time in their home or neighbourhood than a younger, employed adult, who may spend a greater proportion of their daily life in the workplace. Similarly, research on the geographic spaces of childhood stresses that the places which are experienced most, and are most salient for young people, are very different from those that are important for adults (Matthews \& Limb, 1999; Matthews, Limb, \& Percy-Smith, 1998). These issues of varying individual-level exposure to multiple contexts over time and space mean that current measures of simple universally applied 'neighbourhood' exposures may severely underestimate the total effect of 'context', in its 
A

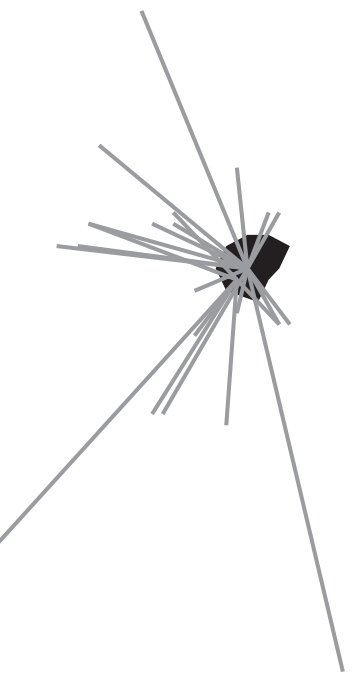

Geocoded fieldnotes revealed that families frequently used resources outside of their local context (defined by the census tract). In the three families depicted here the external resources included medical services, workplaces and training locations, day care and after-school care facilities, shopping centers, food outlets, religious institutions, and the home locations of families and friends (i.e., their social support network).

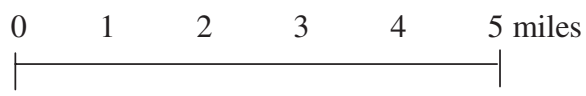

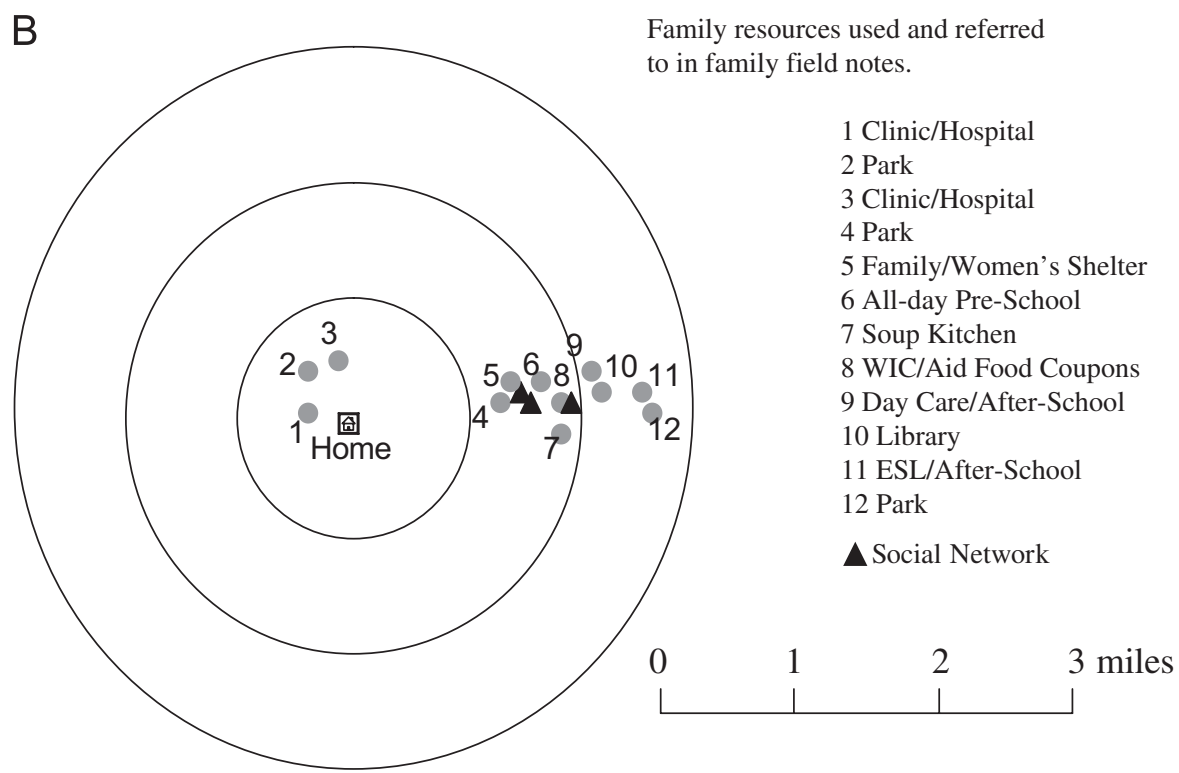

Fig. 2. Census tracts as context in Boston? (A) Shows the movement profiles of three families who reside in the same tract. (B) One family's 'action-space' (Figure courtesy of Stephen Matthews; see Matthews et al., 2005).

myriad of forms and in its multiple locations, on individuals.

To some extent these issues are beginning to be addressed in other areas, particularly in studies of health risks due to physical environmental hazards, and it may be that studies of individual exposure to social, economic and cultural environments might adopt similar strategies. Provided that it is possible to resolve the ethical issues involved, one could also envisage the greater utilization of increasingly inexpensive GPS (global positioning system) technology in order to trace an individual's course through multiple 'contexts' such as work, school and neighbourhood that differ in terms of their health-promoting or health-damaging features. From an environmental epidemiology perspective it has been argued that this approach would greatly enhance the ability of researchers to study environmental risk-factors for disease (see Croner, Sperling, \& Broome, 1996; Nuckols, Ward, \& Jarup, 2004). As an example, Rodriguez, Brown, and Troped (2005) used GPS to demonstrate that less than half of the physical exercise taken by monitored subjects took place within their local residential 
neighbourhoods and thus it is not hard to envisage that these approaches could be extended to more accurately characterize exposures to different social and built environments potentially important for health.

A greater emphasis on the varying contribution of different 'contexts' over time and space would be consistent with current theories about the contributions of lifecourse factors to adult health (Davey Smith, 2003; Graham, 2000). Though research using this approach has shown that residential location in early life may have significance for health in old age (Curtis, Southall, Congdon, \& Dodgeon, 2004), it may be just as important for contextual studies to begin to understand not just the lifecourse of individuals, but also the social and economic trajectories of the places which they inhabit. Such an approach could also begin to address questions about how the changing composition of area populations affects the production of place. For example, more attention needs to be paid to the study of how selective migration (which results in varying spatial concentrations of individuals based on their health or socio-economic position) affects the health of residents (e.g. Boyle, Gattrel, \& DukeWilliams, 1999; Chaix et al., in press; Cox, Boyle, Davey, \& Morris, 2005).

Relational perspectives on place also encourage a greater focus on the position of places relative to each other. Studies often ignore issues of spatial autocorrelation and assume that conditions in each locality operate on population health independently of conditions in other areas. When spatial auto-correlation is considered it is often treated as a "nuisance" (in statistical terms), which needs to be accounted for in order for estimates derived from statistical models (which usually assume independence of outcomes across areas) to be valid. But this spatial correlation may itself be of substantive interest and worthy of investigation. For example, it is often the case that areas with similar conditions are clustered together in space and this clustering may in turn exacerbate the positive or negative impact of local conditions; thus the effect of characteristics of the local area may be modified by features of surrounding areas. The presence of clustering may also reflect the local impact of processes operating at a wider, regional, scale. Some ecological and multilevel analyses of health have begun to employ techniques which model these spatial dependencies more explicitly (Auchincloss, DiezRoux, Brown, O'Meara, \& Raghunathan, in press; Curtis et al., 2006; Chaix et al., 2006; Morenoff, 2003;
Pascutto, Wakefield et al., 2000) However, moving beyond places as "independent" units and incorporating the potential health effects of features of other nearby places remains a major challenge in research on neighbourhood and place effects.

As we argued earlier, the connections between places that are physically distant from each other may be important for individual health from a relational perspective. This implies that there should be greater attention to flows of capital, culture and people between geographically distant places (Glass, 2006; Janes, 2006). This perspective has been appreciated for some time in geographical research on the diffusion of epidemics, which often incorporates information about the position of places in regional or global hierarchies of settlements, ranked by their size or dominance in the urban system (see Löytenen \& Arbona, 1996; Meade \& Earickson, 2002). Such perspective has also been applied in other branches of geographical enquiry, particularly the 'new' economic geography of regions and nations (Yeung, 2005), and we might usefully apply these understandings to health.

Future research may develop improved methods for assessing the position of places as nodes in local, regional and transnational 'flows' of information and other resources. For example, geographical research on health is beginning to consider the contribution of telecommunications to geographical variations in access to medical care (Marsh, 1998). Several geographers (e.g. Cutchin, 2000, 2002; Löytenen, 2000) have called for greater emphasis on these questions and Cutchin (2002) points out that the rise of telemedicine will require a new approach to the ways that technologies, organizations and territories interact. Researchers in other disciplines have already debated how far there is potential for telemedicine to change the pattern of access to health care for remote rural populations and underserved deprived populations (Mitchell, 1999; Swanson, 1999; Whitten \& Cook, 1999). The significance of telecommunications goes beyond the organization of delivery of medical services and includes wider issues of access to information and knowledge about health, risks to health and a range of medical and alternative therapies.

\section{Spatial scale and the production of unhealthy places}

A relational perspective allows place to be defined as a result of endogenous and exogenous processes operating at a variety of spatial scales. We can 
conceive, for example, that trends in regional economies, national and regional environmental pollution, national or supra-national regulatory policies and the action of trans-national organizations and entities can all define the 'local' and other contexts in differing ways and this in turn contributes to the spatial distribution of health outcomes. At least some of these may be best identified at a broad 'contextual' scale, even though their local impact may vary.

These more distal, exogenous processes may originate at a range of spatial scales and similarly have effects on health that are expressed to varying degrees at varying levels of scale. Thus contextual processes can also be seen as attributes of larger macro-scale contexts in which lower-level contexts are themselves embedded and contextual influences originating at a larger-scale can have local expression. A relational approach thus allows places not just to have fixed characteristics but to be dynamic and constantly evolving entities which have positive and negative consequences for the people located within them.

The majority of existing epidemiological research on place and health has focused on a single spatial scale, generally that of local areas or "neighbourhoods". This has been an important first step in the re-discovery of place in health research. However, as previously noted (Cummins, Macintyre, Davidson, \& Ellaway, 2005; Diez-Roux, 1998; Macintyre et al., 2002) broadening our thinking to encompass a variety of spatial scales (regional, national, international) potentially relevant to different health-related processes is an important requirement for development in the field. As we have demonstrated, thinking relationally about place has important implications for thinking about the appropriate scale at which potentially health damaging features of 'context' originate. This implies that health and non-health policies that focus on contextual mechanisms would need to consider carefully what the appropriate contextual level for action might be. This discussion suggests that contextual analyses should ideally seek to examine processes and effects operating at spatial scales other than the local neighbourhood.

Cartier's (2003) discussion of the individual experience of continuing care for an elderly relative is an example of how macro level policy impinges on individual, local experience, and provides an interesting example of the scope for using qualitative research to explore the impact of macro level processes. Some research using extensive data sets to model health variation statistically also has made interesting use of information at various scales. One illustration is a study by Congdon, Shouls, and Curtis (1997) which showed how regional variation among small areas persisted even when the local levels of social and economic deprivation were controlled for, adding to evidence that the north/ south divide in health in the UK is not necessarily explained by factors that vary locally but may also depend on broader scale environmental variables operating at the national scale.

\section{Development of relational geographies: the example of food consumption and diet}

In this part of the paper we consider how the perspectives that we have discussed above can fit together to enhance our understanding of the ways that places relate to health. One illustration is provided by studies of place effects on food consumption and diet. Contextual effects on diet based on the 'food desert' model have been chiefly conceived as the product of two related pathways concerned with neighbourhood physical accessibility to food: access to foods for home consumption from grocery stores and supermarkets and access to ready-made food from take-aways and restaurants for home and out-of-home consumption (see Cummins \& Macintyre, 2006, for a review). This view supposes that the spatial organization of such environmental influences exerts an effect on an individual's health that is independent of the individual's own characteristics. The model assumes that individuals behave in rather similar ways and range over their neighbourhood in a limited manner for the purchase of food items. Thus, it is argued, differing densities of physical opportunities to consume a good diet are translated into differences in diet and ultimately in health.

A relational perspective allows for a much more nuanced view of interactions between people and their local food environment. Early work undertaken by Dobson, Beardsworth, Keil, and Walker (1994) suggested that families on low incomes did not routinely use better quality retail provision even if locally available and instead shopped little and often at local discount supermarkets. These families did not have the financial resources to commit income to buy in bulk or in advance from large supermarkets or food co-operatives. Thus we can hypothesise that if any improvement in large-scale 
local food resources had been achieved in physical terms, 'relational' barriers of social distance might make it problematic for some residents to realize the benefit that improvements in neighbourhood food infrastructure may bring. Some confirmatory indications of this hypothesis can be found in the qualitative component of a recent study of the effect on diet of improving the local food retail environment in a deprived urban area (Cummins, Petticrew, Findlay, Higgins, \& Sparks, 2005; Cummins, Findlay, Petticrew, \& Sparks, in press). Interviews with local residents in an area where new retail facilities had been provided raised questions of boundary and ownership of neighbourhood food retail resources - that is, definitions of what constituted local and appropriate food access for different individuals. Even though the new retail provision was widely perceived to have increased the range and choice of food locally, it was also seen as a temptation to spend beyond your means; as one respondent remarked.

“'It's no' cheap, know what I mean? It's... it's the size of it ... by the time you've got round it, you've spent about three hundred quid for your messages [food shopping]". (30 year-old woman, unemployed, no children) (Cummins et al., in press).

Interestingly, one respondent in this study continued to shop for food in a location that was several miles from her current address as this was where she grew up and had lived for many years. For this individual, even though her 'neighbourhood' food resource was physically distant, it was relationally proximate, through previously established social connections and thus changes in this 'extra-local' place might be conceived as more important for her diet rather than any local change in food provision.

Taking a relational perspective still further, local availability and consumption of healthy foods is determined not only by features of the local area itself (such as local retail outlets and the behaviour and preferences of local consumers) but also by the structural relationships between the local area and the wider 'context' within which it is located (such as: competing retail facilities in neighbouring areas; the policies and distribution systems of national and international retail marketing chains; access to goods through virtual networks; 'online' shopping; government policy in taxing and regulating the sale of goods and influencing public behaviour through health promotion. Murdoch et al. (2000) discuss the relevance of Actor Network Theory and Conventions Theory to the interpretation of agri-business and the food industry. They use the example of small scale food producers who trade on the reputation of their product in terms of its quality and also its association with a particular setting or region.

Operationalizing context at the supra-national and national scale we can see further illustrations of how the local and the global are closely interconnected, with variable impacts for different social groups. For example, Veerman, Barendregt, and Mackenbach (2006) have estimated the effect on fruit and vegetable consumption among the Dutch population if the pan-European Common Agricultural Policy (CAP) were to be abolished (an act that would have the effect of lowering food prices across Europe). They suggest that the national level population impact of changes in wider European agricultural policy might be minimal, but speculate that within a country, social inequalities in diet might be reduced as a result of increased demand for fruit and vegetables amongst low income groups in response to reductions in price. Similarly, analysis of the contribution of national level farm policy to obesity in the US has suggested that policies geared towards driving down prices for corn and soybeans have allowed the price of high fructose corn syrup and trans-fats to decrease, contributing to the manufacture of low-priced, calorie-dense processed foods, while prices for items beneficial for health such as fruits and vegetables, grown with relatively little government support, have steadily increased (Schoonover \& Muller, 2006).

Macro-level contextual processes are not limited to the effects of actions taken by governments and institutions. Global commercial decisions by transnational corporations may have (unintended) local health effects. The recent introduction of a low-cost menu (The Dollar Menu in the US and The Poundsaver Menu in the UK) by MacDonalds has increased total sales by $33 \%$ after a several years of declining revenue. These menus consist entirely of high-fat, high-calorie foods and have an associated marketing campaign that targets those on low incomes, children and ethnic minorities (Warner, 2006). This, coupled with evidence that the company locates outlets in areas of deprivation (Cummins, McKay, \& Macintyre, 2005), suggests that decisions executed globally may exert a local 'contextual' effect by stimulating local demand for diets that differentially promote obesity in deprived 
areas and among low income or ethnic minority groups. These processes operating across different scales highlight the importance of making interventions through macro- as well as micro-level policy to encourage healthy eating. This suggests that there may be novel ways to design local policies which build on the local embeddedness of certain sectors of the food industry, while taking macro-level initiatives with respect to the parts of the industry that operate globally or nationally.

\section{Conclusion}

The recent resurgence of interest in place and health has been mainly based on a traditional, Euclidian conception of space and place and this may be one reason why the relative magnitude of risk ascribed to 'place' is limited when compared to individual-level factors. In this paper we have proposed an alternative view, utilizing a 'relational' perspective, which might offer a deeper understanding of how 'place' affects population health.

In particular, we have suggested that if we are to incorporate relational understandings of how place influences health into empirical analyses we should do three things. Firstly, collapse the false dualism of context and composition by recognising that there is a mutually reinforcing and reciprocal relationship between people and place. Having such a view prompts us to analyse the processes and interactions that occur between people and the social and physical resources in their environment. Secondly, recognize that 'context' and 'place' varies in time and space. Charting an individual's personal geography through multiple 'places' and 'contexts' over the day, week, month or even the lifecourse, will give us improved measures of exposure and allow us not only to understand which environments are most salient for health in terms of location and duration but also how an individuals personal characteristics mediate this relationship. Thirdly, incorporate scale into the analysis of 'contexts' relevant for health. Understanding the appropriate level, from the local to the global, at which 'contextual' processes and actors operate as well as the spatial scale at which their impacts are expressed, is important in order to deliver effective 'contextual' policy interventions.

There is little doubt that existing empirical research has been highly effective in putting 'place' back on the agenda for population health and investigating how social inequalities in health are created and maintained. However, advancing our understanding of how places relate to health will require moving beyond existing conceptualizations of 'place' in empirical research. This development is necessary in order to fully comprehend the complex relational spatial interdependencies which exist between people and places. Recognizing that individuals can become relationally embedded in multiple health damaging and health promoting environments, across time and space, and at multiple scales is crucial if we are to further understand the importance of 'place' in the generation of health inequalities.

\section{Acknowledgements}

This paper was written while Steven Cummins was a Visiting Scholar at the Centre for Social Epidemiology \& Population Health at the University of Michigan. He would like to thank them for hosting his visit, and allowing him to attend lectures, meetings and classes funded by the Robert Wood Johnson Foundation Health \& Society Scholars Program. Steven Cummins is supported by a UK Medical Research Council Special Fellowship in Health of the Public. Sally Macintyre is also funded by the MRC. Ana V. Diez Roux is funded in part by R24 HD047861 and by the Robert Wood Johnson Health and Society Scholar's Program.

\section{References}

Addy, C. L., Wilson, D. K., Kirtland, K. A., Ainsworth, B. E., Sharp, P., \& Kimsey, D. (2004). Associations of perceived social and physical environmental supports with physical activity and walking behavior. American Journal of Public Health, 94, 440-443.

Airey, L. (2003). Nae as nice a scheme as it used to be: lay accounts of neighbourhood incivilities and well-being. Health \& Place, 9, 129-137.

Auchincloss, A. H., Diez-Roux, A. V., Brown, D. G., O’Meara, E. S., \& Raghunathan, T. E. (2007). Insulin resistance is positively associated with distance to wealthy areas: The Multi-Ethnic Study of Atherosclerosis. American Journal of Epidemiology, 165(4), 389-397.

Berkman, L., Glass, T., Brissette, I., \& Seeman, T. (2000). From social integration to health: Durkheim in the new millennium. Social Science \& Medicine, 51, 843-857.

Boyle, P., Gattrel, A., \& Duke-Williams, O. (1999). The effect on morbidity of variability in deprivation and population stability in England and Wales: An investigation at small area level. Social Science \& Medicine, 49, 791-799.

Carpiano, R. (2006). Towards a neighbourhood resource based theory of social capital for health; can Bourdieu and sociology help? Social Science \& Medicine, 62(1), 165-175. 
Cartier, C. (2003). From home to hospital and back again: Economic restructuring, end of life and the gendered problem of place-switching health services. Social Science \& Medicine, 2289-2301

Castree, N. (2004). Differential geographies: Place, indigenous rights and 'local' resources. Political Geography, 23, 133-167.

Chaix, B., Leyland, A., Sabel, C., Chauvin, P., Rastam, L., Kristerrsson, H., et al. (2006). Spatial clustering of mental disorders and associated characteristics of the neighbourhood context in Malmo, Sweden, in 2001. Journal of Epidemiology \& Community Health, 60, 427-435.

Chaix, B., Merlo, J., \& Chauvin, P. (2005). Comparison of a spatial approach with the multilevel approach for investigating place effects on health: The example of healthcare utilisation in France. Journal of Epidemiology \& Community Health, 59(6), 517-526.

Chaix, B., Rosvall, M., Lynch, J., \& Merlo, J. (in press). Disentangling contextual effects on cause-specific mortality in a longitudinal 23-year follow-up study: Impact of population density or socioeconomic environment? International Journal of Epidemiology.

Congdon, P., Shouls, S., \& Curtis, S. (1997). A multi-level perspective on small area health and mortality: A case study of England and Wales. International Journal of Population Geography, 3, 243-263.

Conradson, D. (2005). Landscape, care and the relational self: Therapeutic encounters in rural England. Health \& Place, 11(4), 337-348.

Conradson, D., \& Latham, A. (2005). Attending to everyday practices and mobilities. Journal of Ethnic and Migration Studies, 31(2), 227-233.

Cox, M., Boyle, P., Davey, P., \& Morris, A. (2005). Does healthselective migration following diagnosis strengthen the relationship between Type 2 diabetes and deprivation? In Paper presented at international symposium in medical geography, Forth Worth Texas, July 2005.

Croner, C., Sperling, J., \& Broome, F. (1996). Geographic information systems (GIS): New perspectives in understanding human health and environmental relationships. Statistics in Medicine, 15(17,18), 1961-1977.

Cummins, S., Findlay, A., Petticrew, M., \& Sparks, L. (in press). Reducing inequalities in health and diet: The impact of food retail development. Environment \& Planning A.

Cummins, S., \& Macintyre, S. (2006). Food environments and obesity - neighbourhood or nation? International Journal of Epidemiology, 35, 100-104.

Cummins, S., Macintytre, S., Davidson, S., \& Ellaway, A. (2005). A methodology for measuring neighbourhood social and material context: Generation and interpretation using routine and non-routine data. Health \& Place, 11, 249-260.

Cummins, S., McKay, L., \& Macintyre, S. (2005). McDonald's restaurants and neighbourhood deprivation in Scotland \& England. American Journal of Preventive Medicine, 4, 308-310.

Cummins, S., Petticrew, M., Findlay, A., Higgins, C., \& Sparks, L. (2005). Large-scale food retailing as health intervention: Quasiexperimental evaluation of a natural experiment. Journal of Epidemiology \& Community Health, 59, 1035-1040.

Curtis, S., Copeland, A., Fagg, J., Congdon, P., Almog, M., \& Fitzpatrick, J. (2006). The ecological relationship between deprivation, social isolation and rates of hospital admission for acute psychiatric care: A comparison of London and New York City. Health and Place, 12(1), 19-37.

Curtis, S., \& Rees-Jones, I. (1998). Is there a place for geography in the analysis of health inequality? Sociology of Health and Illness, 20, 645-672.

Curtis, S., Southall, H., Congdon, P., \& Dodgeon, B. (2004). Area effects on health variation over the life-course: Analysis of the longitudinal study sample in England using new data on area of residence in childhood. Social Science \& Medicine, $58,57-74$.

Cutchin, M. (2000). Telemedicine and regionalization: Conceptualizing the medical geography of a new frontier. In Paper presented to the 9th international symposium in medical geography, 3-7 July, Montreal, Quebec, Canada.

Cutchin, M. (2002). Virtual medical geographies: Conceptualizing telemedicine and regionalization. Progress in Human Geography, 26(1), 19-39.

Davey Smith, G. (Ed.). (2003). Health inequalities: Lifecourse perspectives. Bristol: The Policy Press.

Davidson, R., \& Hunt, K. (2006). Location, location, location. The role of experience of disadvantage in lay perceptions of the causes of area inequalities in health. Social Science \& Medicine, under review.

Diez-Roux, A. (1998). Bringing back context into epidemiology: Variables and fallacies in multilevel analysis. American Journal of Public Health, 88(2), 216-222.

Diez-Roux, A. (2000). Multi-level analysis in public health research. Annual Review of Public Health, 21, 171-192.

Diez-Roux, A. (2004). The study of group level variables in epidemiology. Rethinking variables, study designs and analytical approaches. Epidemiologic Reviews, 26, 104-111.

Dobson, B., Beardsworth, A., Keil, T., \& Walker, R. (1994). Diet, choice and poverty: Social cultural and nutritional aspects of food consumption among low-income families. Loughborough: Family Policy Studies Centre.

Duncan, C., \& Jones, K. (1993). Do places matter? A multi-level analysis of regional variation in health related behaviour in Britain. Social Science and Medicine, 37, 725-733.

Emirbayer, M. (1997). Manifesto for a relational sociology. American Journal of Sociology, 103, 281-317.

Eschbach, K., Mahnken, J. D., \& Goodwin, J. S. (2005). Neighborhood composition and incidence of cancer among Hispanics in the United States. Cancer, 103(5), 1036-1044.

Fagg, J., Curtis, S., Clark, C., Congdon, P., \& Stansfeld, S. (2007). The relationships between socio-economic environment in small areas and neighbourhood perceptions and mental health among adolescents in an inner city setting. Journal of Environmental Psychology. Under Review.

Fagg, J., Curtis, S., Congdon, P., \& Stansfeld, S. (2006). Psychological distress among adolescents, and its relationship to individual, family and area characteristics: Evidence from East London, UK. Social Science \& Medicine, 64, 636-648.

Frohlich, K., Corin, E., \& Potvin, L. (2001). A theoretical proposal for the relationship between context and disease. Sociology of Health \& Illness, 23, 776-797.

Frohlich, K., Potvin, L., Chabot, \& Corin, E. (2002). A theoretical and empirical analysis of context: Neighbourhoods, smoking and youth. Social Science \& Medicine, 54, 1401-1417.

Giles-Corti, B., \& Donovan, R. (2003). Relative influences of individual, social environmental, and physical environmental correlates of walking. American Journal of Public Health, 93, 1583-1589. 
Glass, T. (2006). Culture in epidemiology - the 800 pound gorilla? International Journal of Epidemiology, 35, 259-261.

Graham, H. (2000). The challenge of health inequalities. In H. Graham (Ed.), Understanding health inequalities. Buckingham: Open University Press.

Graham, S., \& Healy, P. (1999). Relational concepts of space and place: Issues for planning theory and practice. European Planning Studies, 7, 623-646.

Harvey, D. (1989). The condition of postmodernity. Oxford: Blackwell.

Harvey, D. (1996). Justice, nature and the geography of difference. Oxford: Blackwell.

Hortulanus, R. (2000). The development of urban neighbourhoods and the benefits of indication systems. Social Indicators Research, 50, 209-224.

Hudson, R. (2004). Conceptualising economies and their geographies: Spaces, flows and circuits. Progress in Human Geography, 28(4), 447-471.

Janes, C. (2006). Culture, cultural explanations and causality. International Journal of Epidemiology, 35, 261-263.

Jonas, A. (2006). Pro-scale: Further reflections on the 'scale debate' in human geography. Transactions of Institute of British Geographers, 31, 399-406.

Jones, K., \& Moon, G. (1993). Medical geography: Taking space seriously. Progress in Human Geography, 17, 515-524.

Kearns, R. (1993). Place and health: Toward a reformed medical geography. Professional Geographer, 45, 139-147.

Kearns, R., \& Joseph, A. (1993). Space in it's place - developing the link in medical geography. Social Science \& Medicine, 37, 711-717.

Kwan, M. P. (2004). GIS methods in time-geographic research: Geo-computation and geovisualization of human activity patterns. Geografiska Annaler (Series B), 86(4), 267-280.

Kwan, M. P., \& Lee, J. (2004). Geovisualization of human activity patterns using 3-D GIS: A time-geographic approach. In M. F. Goodchild, \& D. G. Janelle (Eds.), Spatially integrated social science. New York: Oxford University Press.

Kwan, M. P., Murray, A. T., O'Kelly, M. E., \& Tielfelsdorf, M. (2003). Recent advances in accessibility research: Representation, methodology and applications. Journal of Geographical Systems, 5, 129-138.

Latour, B. (1996). On actor-network theory - a few clarifications. Soziale Welt-Zeitschrift fur Sozialwissenschaftliche forschung und praxis, 47(4), 369 Also available on: http://www.nettime.org/ Lists-Archives/nettime-1-9801/msg00019.html (accessed 10/09/06).

Löytenen, M. (2000). Telemedicine and the geography of health. In Paper presented to the 9th international symposium in medical geography. 3-7 July, Montreal, Quebec, Canada.

Löytenen, M., \& Arbona, S. (1996). Forecasting the AIDS epidemic in Puerto Rico. Social Science \& Medicine, 42(7), 997-1010.

Macintyre, S., \& Ellaway, A. (2003). Neighbourhoods and health: An overview. In I. Kawachi, \& L. Berkman (Eds.), Neighbourhoods and health. Oxford: Oxford University Press.

Macintyre, S., Ellaway, A., \& Cummins, S. (2002). Place effects on health: How can we operationalise, conceptualise and measure them? Social Science \& Medicine, 55, 125-139.

Macintyre, S., McIver, S., \& Sooman, A. (1993). Area, class and health: Should we be focusing on people or places? Journal of Social Policy, 22, 213-234.

Marsh, A. (1998). The creation of a global telemedical information society. International Journal of Medical Informatics, 49(2), 173-193.
Marston, S., Jones, J., \& Woodward, K. (2005). Human geography without scale. Transactions of Institute of British Geographers, 30, 416-432.

Martinez, M. L., Black, M. M., \& Starr, R. H. (2002). Factorial structure of the perceived neighborhood scale (PNS): A test of longitudinal invariance. Journal of Community Psychology, $30,23-43$.

Massey, D. (1999). Power geometries and the politics of timespace. Heidelberg: Heidelberg University.

Massey, D. (2005). For space. London: Sage.

Matthews, H., \& Limb, M. (1999). Defining an agenda for the geography of children: Review and prospect. Progress in Human Geography, 23(1), 61-90.

Matthews, H., Limb, M., \& Percy-Smith, B. (1998). Changing worlds: The microgeographies of young teenagers. Tijdschrift voor Economische en Sociale Geografie, 89(2), 193-202.

Matthews, S., Detwiler, J., \& Burton, L. (2005). Geo-ethnography: Coupling geographic information analysis techniques with ethnographic methods in urban research. Cartographica, 40(4), 75-90.

Meade, M., \& Earickson, R. (2002). Medical geography (2nd ed.). New York: Guilford Press.

Mitchell, J. (1999). The uneven diffusion of telemedicine services in Australia. Journal of Telemedicine and Telecare, 5(1), 45- 47.

Mitchell, R. (2001). Multi-level modelling might not be the answer. Environment \& Planning A, 33, 1357-1360.

Morenoff, J. (2003). Spatial dynamics of birth weight. American Journal of Sociology, 108(5), 976-1017.

Murdoch, J. (1998). The spaces of actor network theory. Geoforum, 29(4), 357-374.

Murdoch, J., Marsden, T., \& Banks, J. (2000). Quality, nature and embeddedness: Some theoretical considerations in the context of the food sector. Economic Geography, 76(2), $107-125$.

Neeleman, J., Wilson-Jones, C., \& Wessely, S. (2005). Ethnic density and deliberate self harm: A small area study in south east London. Journal of Epidemiology and Community Health, $55,85-90$.

Nuckols, J., Ward, M., \& Jarup, L. (2004). Using geographic information systems for exposure assessment in environmental epidemiology studies. Environmental Health Perspectives, 112(9), 1007.

Pascutto, C., Wakefield, J., et al. (2000). Statistical issues in the analysis of disease mapping data. Statistics in Medicine, 19, 2493-2519.

Pickett, K., \& Pearl, M. (2001). Multilevel analyses of neighbourhood socioeconomic context and health outcomes: A critical review. Journal of Epidemiology \& Community Health, 55, 111-122.

Popay, J., Thomas, C., Williams, G., Bennett, S., Gattrell, A., \& Bostock, L. (2003). A proper place to live: Health inequalities, agency and the normative dimensions of space. Social Science \& Medicine, 57, 55-69.

Popay, J., Williams, G., Thomas, C., \& Gatrell, A. (1998). Theorising inequalities in health: The place of lay knowledge. Sociology of Health \& Illness, 20(5), 619-644.

Raudenbush, S., \& Sampson, R. (1999). Ecometrics: Towards a science of assessing ecological settings, with application to the systematic social observation of neighborhoods. Sociological Methodology, 29, 1-41.

Rodriguez, D., Brown, A., \& Troped, P. (2005). Portable global positioning units to complement accelerometry-based 
physical activity monitors. Medicine and Science in Sports and Exercise, 37(11), S572-S581 (Suppl. S).

Salais, R., \& Storper, M. (1993). Les mondes du production. Editions de l'Ecole des hautes études en sciences sociales. Paris.

Sampson, R., Morenoff, J., \& Gannon-Rowley, T. (2002). Assessing neighbourhood effects: Social processes and new directions in research. Annual Review of Sociology, 28, 443-478.

Schoonover, H., \& Muller, M. (2006). Food without thought. How US farm policy contributes to obesity. Minneapolis: Institute for Agriculture \& Trade Policy.

Shouls, S., Congdon, P., \& Curtis, S. (1996). Modelling inequality in reported long term illness in the UK: Combining individual and area characteristics. Journal of Epidemiology and Community Health, 50(3), 366-376.

Smith, S., \& Easterlow, D. (2005). The strange geography of health inequalities. Transactions of the Institute of British Geographers, 30, 173-190.

Stafford, M., Cummins, S., Macintyre, S., Ellaway, A., \& Marmot, M. (2005). Gender differences in the associations between health and neighbourhood environment. Social Science \& Medicine, 60, 1681-1692.

Subramanian, S., Acevedo-Garcia, D., \& Osypuk, T. (2005). Racial residential segregation and geographic heterogeneity in black/ white disparity in poor self-rated health in the US: A multilevel statistical analysis. Social Science \& Medicine, 60, 1667-1679.

Subramanian, S. V., Jones, K., \& Duncan, C. (2003). Multilevel methods for public health research. In I. Kawachi, \& L. F. Berkman (Eds.), Neighborhoods and health (pp. 65-111). New York: Oxford University Press.
Swanson, B. (1999). Information technology and under-served communities. Journal of Telemedicine and Telecare, 5(2), S3-S10.

Veerman, J., Barendregt, J., \& Mackenbach, J. (2006). The European common agricultural policy on fruits and vegetables: Exploring potential health gain from reform. European Journal of Public Health, 16(1), 31-35.

Warfa, N., Bhui, K., Craig, T., Curtis, S., Mohamud, S., Stansfeld, S., et al. (2006). Post-migration geographical mobility, mental health and health service utilisation among Somali refugees in the UK: A qualitative study. Health \& Place, 12(4), 503-515.

Warner, M. (2006). Salads or No, Cheap Burgers Revive McDonalds. New York Times, 19th April, p1, pC4.

Watts, M. (1999). Collective wish images: Geographical imaginaries and the crisis of development. In J. Allen, \& D. Massey (Eds.), Human geography today (pp. 85-107). Cambridge: Polity Press.

Watts, M. (2000). Contested communities malignant markets. In C. Cerner (Ed.), People, plants and justice (pp. 21-51). New York: Columbia University Press.

Whitten, P., \& Cook, D. (1999). School-based telemedicine: Using technology to bring health care to inner-city children. Journal of Telemedicine \& Telecare, 5(1), 23-25.

Wilkinson, R. G., \& Pickett, K. E. (2006). Income inequality and health: A review and explanation of the evidence. Social Science \& Medicine, 62, 1768-1784.

Yeung, H. (2005). Rethinking relational economic geography. Transactions of the Institute of British Geographers, 30, 37-51. 